Title: Lewis Acid-Assisted Reduction of Nitrite to Nitric and Nitrous Oxide via the Elusive Nitrite Radical Dianion

Authors:

Valiallah Hosseininasab, ${ }^{l}$ Ida M. DiMucci, ${ }^{2}$ Pokhraj Ghosh, ${ }^{1,5}$ Jeffery A. Bertke, ${ }^{l}$ Siddarth Chandrasekharan, ${ }^{2}$ Charles J. Titus, ${ }^{3}$ Dennis Nordlund, ${ }^{4}$ Jack H. Freed, ${ }^{2}$ Kyle M. Lancaster, ${ }^{2 *}$ and Timothy H. Warren, ${ }^{1,5 *}$

Author Affiliations:

${ }^{1}$ Department of Chemistry, Georgetown University, Box 571227, Washington, DC 20057, USA.

${ }^{2}$ Department of Chemistry and Chemical Biology, Cornell University, 122 Baker Laboratory, Ithaca, New York 14853, United States.

${ }^{3}$ Department of Physics, Stanford University, Stanford, California 94305, USA

${ }^{4}$ Stanford Synchrotron Radiation Lightsource, SLAC National Accelerator Laboratory, Menlo Park, California 94025, USA

${ }^{5}$ Department of Chemistry, Michigan State University, East Lansing, MI 48824, USA.

*email:km1236@cornell.edu; thw@georgetown.edu

Author Contributions:

VH and THW conceived the synthetic approach; VH carried out synthetic experiments; VH and PG performed electrochemical measurements; VH and JAB performed crystallographic analysis; IMD, CJT, and DN collected XAS data, KML, and SC collected EPR data, IMD and KML carried out electronic structure calculations and interpreted spectroscopic data, VH, KML, and THW wrote the manuscript with assistance by JHF.

Competing interests:

The authors declare no competing interests. 


\title{
Lewis Acid-Assisted Reduction of Nitrite to Nitric and Nitrous Oxide via the Elusive Nitrite Radical Dianion
}

\begin{abstract}
Reduction of nitrite anions $\left(\mathrm{NO}_{2}^{-}\right)$takes place in a myriad of environments such as in the soil as part of the biogeochemical nitrogen cycle as well as in acidified nuclear waste. Nitrite reduction typically takes place within the coordination sphere of a redox active transition metal. Lewis acid coordination, however, can dramatically modify the reduction potential of this polyoxoanion to allow for reduction under non-aqueous conditions (-0.74 V vs. NHE). This strategy enables the isolation of a borane-capped nitrite dianion $\left(\mathrm{NO}_{2}{ }^{2-}\right)$ along with its spectroscopic study consistent with reduction to the N(II) oxidation state. Protonation of the nitrite dianion results in facile loss of nitric oxide (NO) while reaction of the nitrite dianion with nitric oxide results in disproportionation to nitrous oxide $\left(\mathrm{N}_{2} \mathrm{O}\right)$ and nitrite, connecting three redox levels in the global nitrogen cycle.
\end{abstract}


Oxyanions are a class of water pollutants of growing concern due to their high solubility in water, their potential toxicity and their negative environmental impacts. ${ }^{1,2}$ Nature has evolved several biochemical pathways capable of facile, selective reduction of oxyanions. The constituent enzymes in these pathways offer inspiration for the design of catalysts purposed toward remediation of oxyanion pollution. ${ }^{3}$ For example, the nitrite anion $\left(\mathrm{NO}_{2}^{-}\right)$is exploited as a terminal electron acceptor during denitrification, where it is progressively reduced to nitric oxide (NO), nitrous oxide $\left(\mathrm{N}_{2} \mathrm{O}\right)$, and ultimately to dinitrogen $\left(\mathrm{N}_{2}\right)$. The initial, selective reduction of $\mathrm{NO}_{2}^{-}$to $\mathrm{NO}$ is mediated by metalloenzymes including cytochrome c oxidase and nitrite reductases that leverage coordination of $\mathrm{NO}_{2}{ }^{-}$to $\mathrm{Fe}$ or $\mathrm{Cu}$ centers. ${ }^{4-7}$ These redox-active metals transfer an electron to $\mathrm{NO}_{2}^{-}$, facilitated both by the Lewis acidity of the metal centers and accompanied by binding of a proton to a nitrite O-atom in nitrite reductase. ${ }^{8,9}$ Either of these binding events may lower the reduction potential of $\mathrm{NO}_{2}{ }^{-}$, rendering electron-transfer more favorable (Figs. 1a and 1b).

Reduction of nitrogen oxyanions also occurs in high level radioactive waste stored in nitrate and nitrite rich aqueous solutions. ${ }^{10}$ Solvated electrons generated radiolytically undergo rapid capture by both nitrate and nitrite to form the dianions $\mathrm{NO}_{3}{ }^{2-}$ and $\mathrm{NO}_{2}{ }^{2-}$ (Fig. 1c). These dianions are extremely short-lived species with lifetimes on the order of $20 \mu \mathrm{s}$ before reaction with water produces $\mathrm{NO}_{2}$ and $\mathrm{NO}$, respectively. ${ }^{11}$

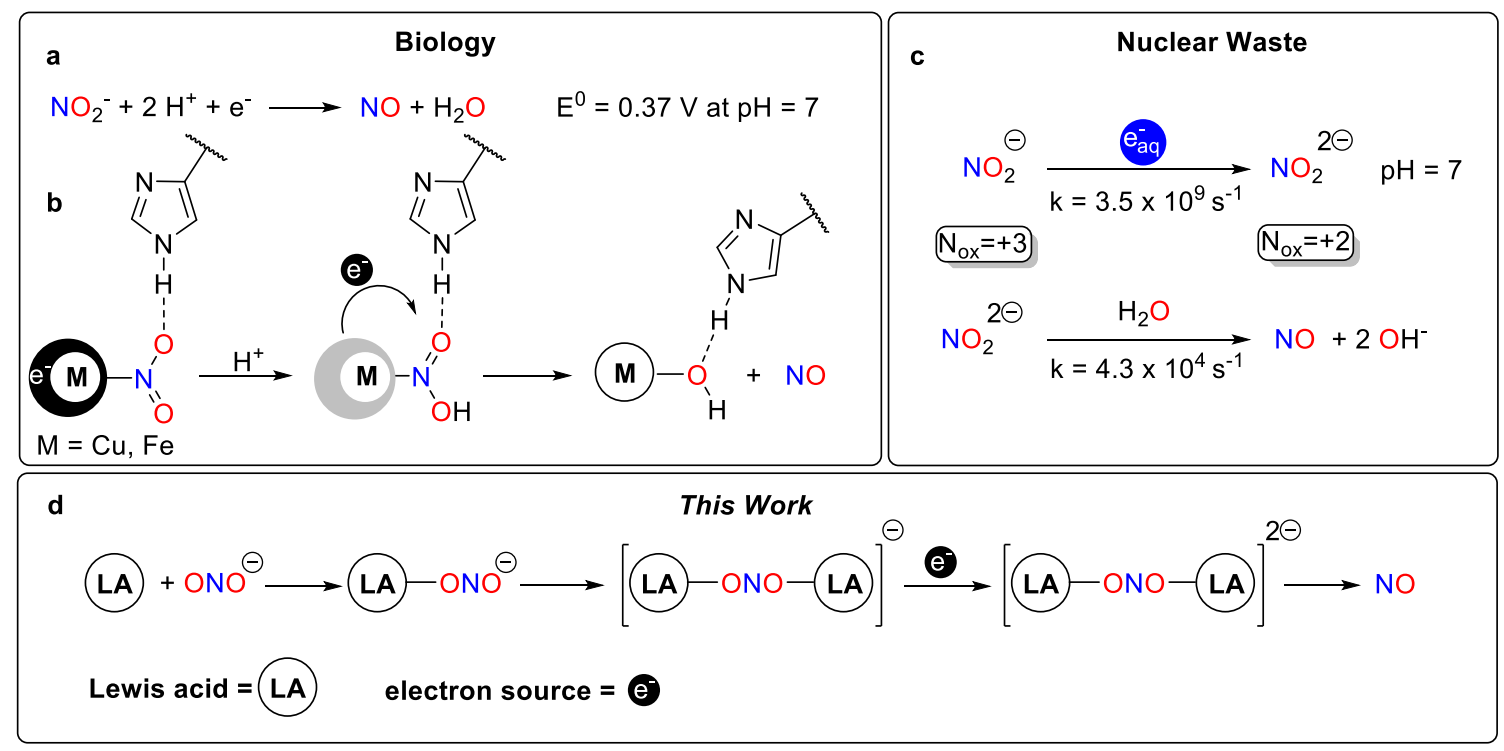

Figure 1 Nitrite reduction in biology and nuclear waste: the role of protons and Lewis acids. a, Reduction potential of nitrite to $\mathrm{NO}$ at $\mathrm{pH} 7$ involves two protons. b, Metal-nitrite coordination, H-bonding networks, and proton transfer facilitate biological nitrite reduction to NO. c, Rapid capture of $\beta$-particles (electrons) by nitrite from radioactive decay to form the nitrite dianion $\mathrm{NO}_{2}{ }^{2-}$ and subsequent proton-induced release of NO. d, Lewis acid coordination enables isolation of nitrite dianion $\mathrm{NO}_{2}{ }^{2-}$. 
To decouple the effects of Lewis acid coordination and proton transfer to an oxyanion during reduction, we explored the effects of coordinating $\mathrm{NO}_{2}{ }^{-}$to a redox innocent Lewis acid. We have previously shown the coordination of the biological nitric oxide reservoir RSNOs to the Lewis acid $\mathrm{B}\left(\mathrm{C}_{6} \mathrm{~F}_{5}\right)_{3}$ in $\mathrm{RSNO}-\mathrm{B}\left(\mathrm{C}_{6} \mathrm{~F}_{5}\right)_{3}$ adducts significantly raises the reduction potential for RSNOs (ca. -1.1 to $-1.3 \mathrm{~V}$ vs. NHE) that enables generation of the $\left[\mathrm{RSNO}-\mathrm{B}\left(\mathrm{C}_{6} \mathrm{~F}_{5}\right)_{3}\right]^{-/ \bullet}$ radical anion at biologically relevant potentials $\left(+0.1\right.$ vs. NHE) ${ }^{12}$ Employing a strong, yet chemically stable capping Lewis acid for each of the two $\mathrm{O}$ atoms of nitrite, this strategy enables the facile reduction of $\mathrm{NO}_{2}{ }^{-}$to its radical dianion $\mathrm{NO}_{2}{ }^{2-}$ without attendant proton transfer. This approach effectively decouples electron-transfer and protonation to enable the characterization and reactivity study of the novel oxyanion $\mathrm{NO}_{2}{ }^{2-}$ that connects $\mathrm{NO}_{2}{ }^{-}, \mathrm{NO}$, and $\mathrm{N}_{2} \mathrm{O}$ representing three redox levels in the global nitrogen reduction cycle.

\section{Results}

Capture of Nitrite Dianion: Synthesis and Characterization. Addition of 1 equivalent $\mathrm{B}\left(\mathrm{C}_{6} \mathrm{~F}_{5}\right)_{3}$ to $\left[\mathrm{Cp}_{2}{ }_{2} \mathrm{Co}\right]\left[\mathrm{NO}_{2}\right]$ (1) in fluorobenzene leads to the formation of $\left[\mathrm{Cp}_{2}{ }_{2} \mathrm{Co}\right]\left[\left(\mathrm{C}_{6} \mathrm{~F}_{5}\right)_{3} \mathrm{~B}-\mathrm{ONO}\right]$ (2) in near quantitative yield (Fig. 2a). The X-ray structure of unsymmetrically capped 2 shows O-bound nitrite to the $\mathrm{B}\left(\mathrm{C}_{6} \mathrm{~F}_{5}\right)_{3}$ with markedly different $\mathrm{N}-\mathrm{O}$ distances of 1.337(10) (capped $\mathrm{O}$ atom) and 1.200(10) $\AA$ (free $\mathrm{O}$ atom), respectively (Supplementary Fig. 30). Treating $\left[\mathrm{Cp}_{2}{ }_{2} \mathrm{Co}\right]\left[\left(\mathrm{C}_{6} \mathrm{~F}_{5}\right)_{3} \mathrm{~B}-\mathrm{ONO}\right]$ (2) with a second equivalent $\mathrm{B}\left(\mathrm{C}_{6} \mathrm{~F}_{5}\right)_{3}$ in fluorobenzene forms the doubly activated nitrite anion in $\left[\mathrm{Cp}_{2}{ }_{2} \mathrm{Co}\right]\left[\left(\mathrm{C}_{6} \mathrm{~F}_{5}\right)_{3} \mathrm{~B}-\mathrm{ONO}-\mathrm{B}\left(\mathrm{C}_{6} \mathrm{~F}_{5}\right)_{3}\right]$ (3) (Fig. 2b). The X-ray structure of $\mathbf{3}$ shows more symmetric NO distances $(1.261(2), 1.225(2) \AA$ ) that result upon coordination of a Lewis acid to each $\mathrm{O}$ atom in nitrite. Lewis acid coordination also results in a contraction of the nitrite O-N-O bond angle to $112.2(7)^{\circ}$ and $109.3(17)^{\circ}$ in mono- and di-capped species $\mathbf{2}$ and $\mathbf{3}$, respectively, compared to the free nitrite anion in $1\left(120.6(6)^{\circ}\right.$; Supplementary Figs. 29-31). 


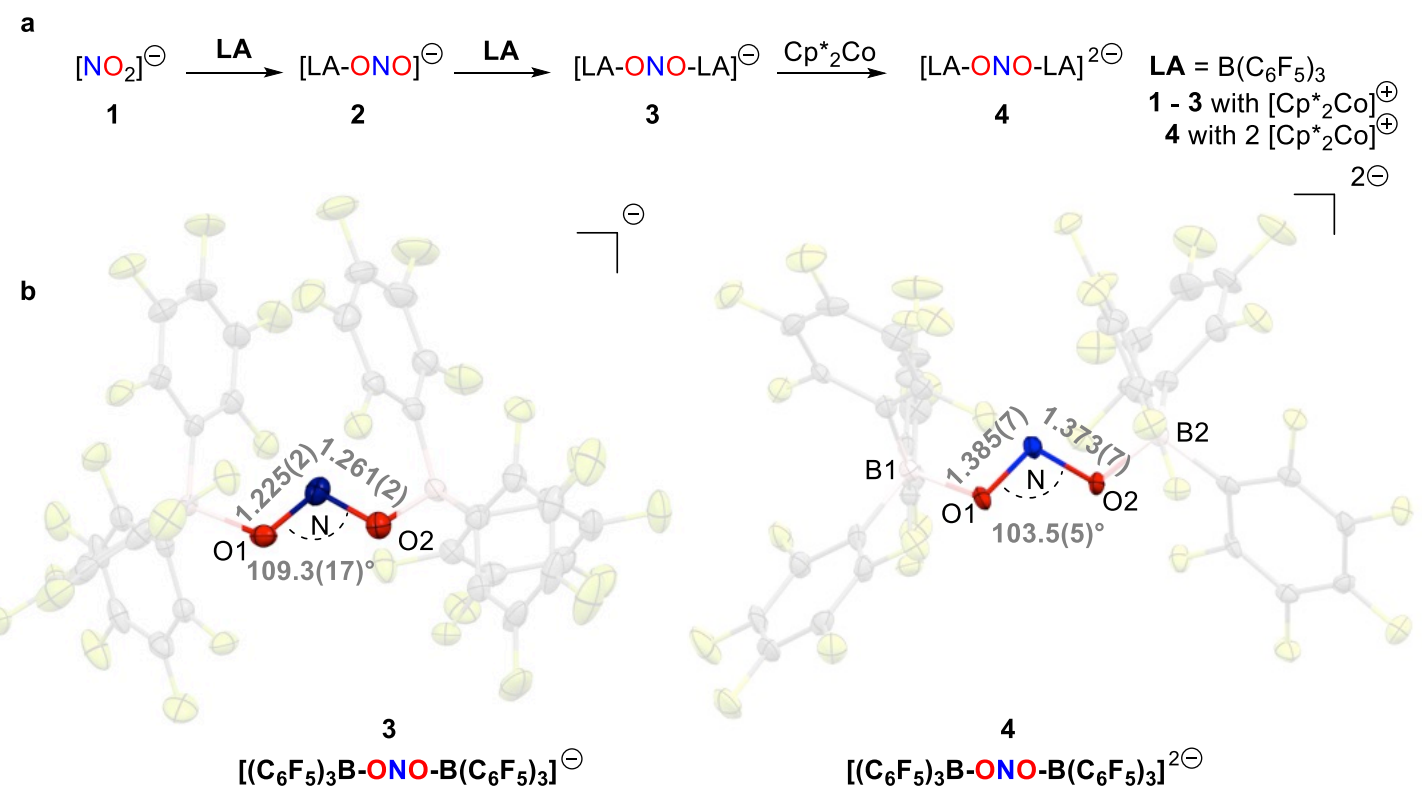

Figure 2 Synthesis and structures of Lewis acid capped nitrite mono- and dianions. a, Synthesis of Lewis acid-capped nitrite anions $\left[\mathrm{Cp}_{2}{ }_{2} \mathrm{Co}\right]\left[\left(\mathrm{C}_{6} \mathrm{~F}_{5}\right)_{3} \mathrm{~B}-\mathrm{ONO}\right]$ (2), $\left[\mathrm{Cp}_{2}{ }_{2} \mathrm{Co}\right]\left[\left(\mathrm{C}_{6} \mathrm{~F}_{5}\right)_{3} \mathrm{~B}-\mathrm{ONO}-\mathrm{B}\left(\mathrm{C}_{6} \mathrm{~F}_{5}\right)_{3}\right]$ (3) and $\left[\mathrm{Cp}_{2}{ }_{2} \mathrm{Co}_{2}\right]_{2}\left[\left(\mathrm{C}_{6} \mathrm{~F}_{5}\right)_{3} \mathrm{~B}-\mathrm{ONO}-\mathrm{B}\left(\mathrm{C}_{6} \mathrm{~F}_{5}\right)_{3}\right]$ (4). b, X-ray structures of nitrite monoanion $\left[\mathrm{Cp}^{*}{ }_{2} \mathrm{Co}\right]\left[\left(\mathrm{C}_{6} \mathrm{~F}_{5}\right)_{3} \mathrm{~B}-\mathrm{ONO}-\mathrm{B}\left(\mathrm{C}_{6} \mathrm{~F}_{5}\right)_{3}\right]$ (3) and dianion $\left[\mathrm{Cp}_{2}{ }_{2} \mathrm{Co}\right]_{2}\left[\left(\mathrm{C}_{6} \mathrm{~F}_{5}\right)_{3} \mathrm{~B}-\mathrm{ONO}-\mathrm{B}\left(\mathrm{C}_{6} \mathrm{~F}_{5}\right)_{3}\right]$ (4) with N-O distances $(\AA)$ and $\mathrm{O}-\mathrm{N}-\mathrm{O}$ angles $\left(^{\circ}\right)$. Each anion is charge-balanced by the $\mathrm{Cp}_{2}{ }_{2} \mathrm{Co}^{+}$cation.

Cyclic voltammetry (CV) studies reveal the effect of the Lewis acid coordination on the reduction potential of free nitrite. Under aqueous conditions, the reduction potential for free nitrite is highly proton dependent, ranging from $+0.98 \mathrm{~V}$ and -0.48 vs NHE at $\mathrm{pH} 0.0$ and 14.0 , respectively. ${ }^{13,14}$ In fluorobenzene with $[\mathrm{PPN}]\left[\mathrm{BAr}_{4}^{\mathrm{F}}\right]\left(\mathrm{Ar}^{\mathrm{F}}=3,5-\left(\mathrm{CF}_{3}\right)_{2} \mathrm{C}_{6} \mathrm{H}_{3}\right)$ as electrolyte, however, neither $\left[\mathrm{Cp}_{2}{ }_{2} \mathrm{Co}\right]\left[\mathrm{NO}_{2}\right]$ (1) nor $\left[\mathrm{Cp}_{2}{ }_{2} \mathrm{Co}\right]\left[\left(\mathrm{C}_{6} \mathrm{~F}_{5}\right)_{3} \mathrm{~B}-\mathrm{ONO}\right]$ (2) exhibits any reduction wave for nitrite or monocapped nitrite anion (Supplementary Fig. 26). Rather, only a wave for $\mathrm{Cp}_{2}{ }_{2} \mathrm{Co}^{+} / \mathrm{Cp}_{2}{ }_{2} \mathrm{Co}$ couple is evident which appears at $-1.35 \mathrm{~V}$ in $\mathbf{2}$. In marked contrast, the cyclic voltammogram of $\left[\mathrm{Cp}_{2}{ }_{2} \mathrm{Co}\right]\left[\left(\mathrm{C}_{6} \mathrm{~F}_{5}\right)_{3} \mathrm{~B}-\mathrm{ONO}-\mathrm{B}\left(\mathrm{C}_{6} \mathrm{~F}_{5}\right)_{3}\right]$ (3) shows a quasi-reversible wave centered at $-0.74 \mathrm{~V}$ vs. NHE that corresponds to the $\left[\left(\mathrm{C}_{6} \mathrm{~F}_{5}\right)_{3} \mathrm{~B}-\mathrm{ONO}-\mathrm{B}\left(\mathrm{C}_{6} \mathrm{~F}_{5}\right)_{3}\right]^{-} /\left[\left(\mathrm{C}_{6} \mathrm{~F}_{5}\right)_{3} \mathrm{~B}-\mathrm{ONO}-\mathrm{B}\left(\mathrm{C}_{6} \mathrm{~F}_{5}\right)_{3}\right]^{2-}$ couple (Supplementary Fig. 27). The addition of a second Lewis acid to the nitrite anion induces a profound electronic effect that facilitates nitrite reduction.

Chemical reduction of $\left[\mathrm{Cp}_{2}{ }_{2} \mathrm{Co}\right]\left[\left(\mathrm{C}_{6} \mathrm{~F}_{5}\right)_{3} \mathrm{~B}-\mathrm{ONO}-\mathrm{B}\left(\mathrm{C}_{6} \mathrm{~F}_{5}\right)_{3}\right]$ (3) with $\mathrm{Cp}_{2}{ }_{2} \mathrm{Co}$ in fluorobenzene effects a color change from yellow to gray (Fig. 2a). Crystallization of the gray product confirms the formation of the borane capped nitrite radical dianion $\left[\mathrm{Cp}_{2}{ }_{2} \mathrm{Co}\right]_{2}\left[\left(\mathrm{C}_{6} \mathrm{~F}_{5}\right)_{3} \mathrm{~B}-\mathrm{ONO}-\mathrm{B}\left(\mathrm{C}_{6} \mathrm{~F}_{5}\right)_{3}\right](4)$ (Fig. 2b). While Lewis acid capped mono- and dianions $\mathbf{3}$ and $\mathbf{4}$ possess similar overall structures, 
the bond lengths and angles in nitrite dianion $\mathbf{4}$ are greatly changed in comparison with nitrite $\mathbf{3}$. In nitrite dianion 4 the $\mathrm{N}-\mathrm{O}$ bonds are significantly elongated (1.385(7), 1.373(7) $\AA$ ) as compared to monoanion 3 (1.225(2), 1.261(2) $\AA$ ) in response to the extra electron present in the nitrite dianion 4. Furthermore, the nitrite $\mathrm{O}$ atoms in dianion $\mathbf{4}$ are more tightly bound to the capping boranes (B-O distances: 1.488(9), 1.490(9) $\AA$ ), consistent with its greater negative charge in comparison to doubly capped nitrite anion 3 (B-O distances: 1.603(3), 1.628(3) $\AA$ ). Moreover, the $\mathrm{O}-\mathrm{N}-\mathrm{O}$ bond angle in dianion $4\left(103.5(5)^{\circ}\right)$ is contracted relative to monoanion $3\left(109.3(17)^{\circ}\right)$. IR spectroscopy reports a significantly lower energy $\mathrm{N}-\mathrm{O}$ stretching frequency for dianion 4 (1010 $\left.\mathrm{cm}^{-1}\right)$ in comparison with monoanion $3\left(1265 \mathrm{~cm}^{-1}\right)$, consistent with a weakening of the $\mathrm{N}-\mathrm{O}$ bonds of nitrite upon one electron reduction.

Electronic Structure of the Nitrite Dianion Core. Qualitative molecular orbital analysis for $\mathrm{NO}_{2}{ }^{2-1-}$ predicts that lowest unoccupied MO (LUMO) of $\mathbf{3} /$ singly occupied molecular orbital (SOMO) of 4 should be an N-localized $\pi^{*}$ combination between $N 2 p_{x}$ and a $O 2 p_{x}$ orbitals (Supplementary Fig. 38). This is confirmed by analysis of electron paramagnetic resonance (EPR) spectra. The continuous wave X-band EPR spectrum obtained at room temperature for 4 (Fig. 3a) reveals the expected isotropic 3-line pattern arising from ${ }^{14} \mathrm{~N}$ hyperfine coupling with $\mathrm{A}_{\text {iso }}\left({ }^{14} \mathrm{~N}\right)=$ 44.0 MHz. Accordingly, the ${ }^{15} \mathrm{~N}$ isotopolog exhibits a 2-line pattern with $\mathrm{A}_{\text {iso }}\left({ }^{15} \mathrm{~N}\right)=62.0 \mathrm{MHz}$ (Fig. 3b). The giso value of 2.005 obtained from both measurements is consistent with a radical comprised solely of light atoms. Frozen-solution spectra recorded at both X- (Fig. 3c) and Q-band (Fig. 3d) (the latter obtained by field-swept echo detection) reveal substantial anisotropy of the ${ }^{14} \mathrm{~N}$ hyperfine values, with the best simulation of the $\mathrm{X}$-band data giving $\mathrm{A}_{\mathrm{x}}=122 \mathrm{MHz}, \mathrm{A}_{\mathrm{y}}=4$ $\mathrm{MHz}$ and $\mathrm{A}_{\mathrm{z}}=6 \mathrm{MHz}$. Assignment of the larger HFC as $\mathrm{A}_{\mathrm{x}}$ is supported by the corresponding Q-band data. The g-values obtained from simulating the Q-band data of $\mathbf{4}$ are $\mathrm{g}_{\mathrm{x}}=1.991, \mathrm{~g}_{\mathrm{y}}=$ 1.996, and $\mathrm{g}_{\mathrm{z}}=1.996$. For completeness, frozen-solution spectra and simulations for the ${ }^{15} \mathrm{~N}$ isotopolog are given in the supporting information. 

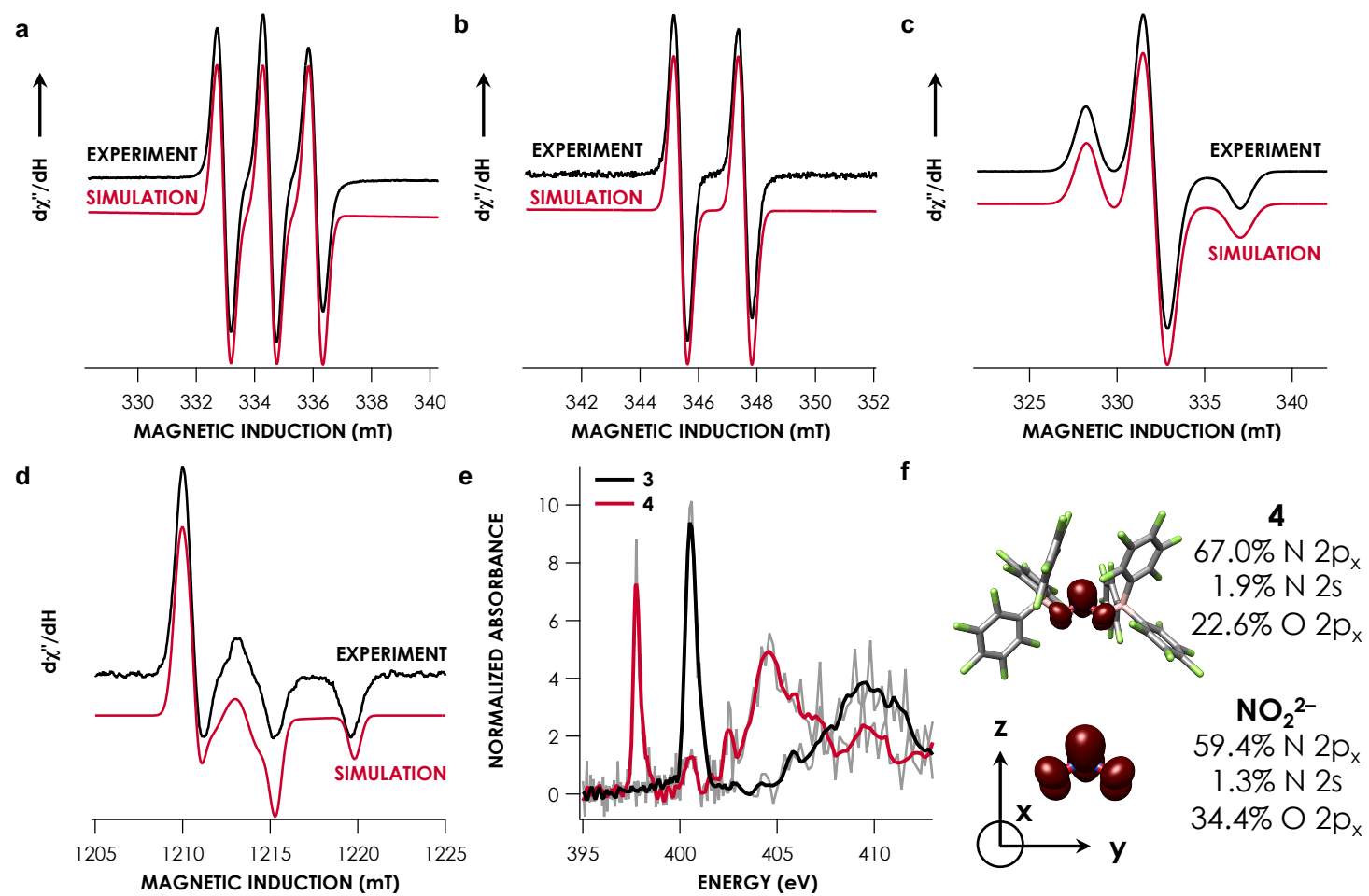

Figure 3 Spectroscopy and calculations. a, $298 \mathrm{~K}$ solution continuous wave (CW) X-band $(9.3886 \mathrm{GHz})$ EPR spectrum of ${ }^{14} \mathrm{~N}-\mathbf{4}(9.7249 \mathrm{GHz})$. b, Solution CW X-band EPR spectrum of ${ }^{15} \mathrm{~N}-4$. c, $96 \mathrm{~K}$ frozen solution $\mathrm{CW}$ X-band $(9.2710 \mathrm{GHz}) \mathrm{EPR}$ of ${ }^{14} \mathrm{~N}-\mathbf{4}$. d, $10 \mathrm{~K}$ field-swept echo-detected Q-band (33.9544 GHz) EPR of ${ }^{14} \mathrm{~N}-4$. Experimental data are in black, simulations are red. e, Smoothed partial fluorescence yield detected N K-edge XAS of 3 (black) and 4 (red). Raw data are in gray. f, B3LYP/def2-TZVP(-f) calculated spin density plots (isovalue $0.002 \mathrm{au}$ ) of the dianion in $\mathbf{4}$ and geometry-optimized $\mathrm{NO}_{2}{ }^{2-}$.

For an electron localized to a MO with substantial $N 2 p_{x}$ character, the $A$ values $\left[A_{x}, A_{y}, A_{z}\right]$ are expected to be [aiso $+T_{x}$, aiso $+T_{y}$, aiso $+T_{z}$ ], where $T$ is the anisotropic value for ${ }^{14} \mathrm{~N}$. Using values tabulated by Morton and Preston, ${ }^{15}$ the value of aiso corresponding to an electron localized to $\mathrm{N} 2 \mathrm{~s}$ is $1811 \mathrm{MHz}$, while an electron localized to $\mathrm{N} 2 \mathrm{p}_{\mathrm{x}}$ should have anisotropic $\left[\mathrm{T}_{\mathrm{x}}, \mathrm{T}_{\mathrm{y}}, \mathrm{T}_{\mathrm{z}}\right]=$ $[4 / 5,-2 / 5,-2 / 5] \times 138.8 \mathrm{MHz}=[111.04,-55.52,-55.52] \mathrm{MHz}$. Using the well-resolved $\mathrm{A}_{\mathrm{x}}$ value to obtain $\mathrm{T}_{\mathrm{x}}$, the unpaired spin in 4 resides in a molecular orbital with $2.5 \% \mathrm{~N} 2 \mathrm{~s}$ and $69 \% \mathrm{~N} 2 \mathrm{p}_{\mathrm{x}}$ character.

$\mathrm{N}$-localization of the reduction of $\mathbf{3}$ to $\mathbf{4}$ is further supported by $\mathrm{N} \mathrm{K}$-edge $(1 \mathrm{~s} \rightarrow 2 \mathrm{p}$ ) XAS (Fig. 3e). The spectrum obtained for 3 has an intense pre-edge feature at $400.6 \mathrm{eV}$ this is shifted to $397.8 \mathrm{eV}$ in $\mathbf{4}$. The intensity of this feature is diminished in $\mathbf{4}$, consistent with occupation of a formerly empty MO. The edge position in the spectrum obtained for 3 appears at ca. $5 \mathrm{eV}$ higher 
energy relative to the edge in $\mathbf{4}$. Together, these are consistent with reduction of $\mathrm{N}$. The intensity of the pre-edge feature in 4 be related to $\mathrm{N} 2 \mathrm{p}$ participation in the acceptor orbital via Equation $(1)^{16}$ :

$$
D_{0}=\frac{\alpha^{2} I_{S} h}{3 n}
$$

Where $D_{0}$ is the pre-edge peak intensity, $h$ is the number of holes, $n$ is the number of photoabsorbers ( $\mathrm{n}$ and $\mathrm{h}=1$ in 4), $I_{\mathrm{s}}$ is the radial dipole integral between $\mathrm{N} 1 \mathrm{~s}$ and $\mathrm{N} 2 \mathrm{p}$, and $\alpha^{2}$ is the $\% \mathrm{~N} 2 \mathrm{p}$ character of the acceptor MO. Using the experimental $\mathrm{D}_{0}$ of 4.2 and the $69 \% \mathrm{~N} 2 \mathrm{p}_{\mathrm{x}}$ character determined via EPR, a value of 18.3 is obtained for $I_{\mathrm{s}}$. This value is smaller than an estimate of $I_{\mathrm{s}}$ obtained by studying a library of $\mathrm{N}$-ligated coordination complexes ${ }^{17}$ and reflects decontraction of the $2 \mathrm{p}$ orbital of the highly electron-rich $\mathrm{N}$-center in $4 .^{18}$

Hybrid density functional theory (DFT) calculations using the B3LYP hybrid density functional and the scalar-relativistically recontracted ZORA-def2-TZVP(-f) basis set on all atoms further support the formulation of $\mathbf{4}$ as containing a $\mathrm{NO}_{2}{ }^{2-}$ core. The calculated spin density occupies a $\mathrm{b}_{1}$-symmetry $\mathrm{O}-\mathrm{N}-\mathrm{O} \pi^{*}$ orbital composed $2 \% \mathrm{~N} 2 \mathrm{~s}$ and $67 \% \mathrm{~N} 2 \mathrm{p}_{\mathrm{x}}$ in excellent agreement with values obtained from EPR (Fig. 2F). The residual spin density resides predominantly on $\mathrm{O}$. Calculated spin Hamiltonian parameters exhibit high fidelity to values extracted from spectral simulations. Time-dependent DFT calculations of the N K-edge XAS confirm that the pre-edge feature in the spectrum obtained for $\mathbf{4}$ corresponds to a promotion from $\mathrm{N} 1 \mathrm{~s}$ to the $\mathrm{b}_{1}$-symmetry SOMO. Additionally, these calculations reproduce the energy shifts observed between $\mathrm{N} \mathrm{K}$ features of $\mathbf{3}$ and 4 (Supplementary Fig. 40).

Given the fidelity of the calculated electronic structure to that deduced from experiment, we sought to examine the role of the capping Lewis acids on the electronic structure of the $\mathrm{NO}_{2}{ }^{2-}$ core. Geometry optimization of the bare anion $\mathrm{NO}_{2}{ }^{2-}$ at this level of theory affords $\mathrm{N}-\mathrm{O}$ distances of $1.372 \AA$ and an angle of $111.5^{\circ}$, consistent with an electron in $\mathrm{O}-\mathrm{N}-\mathrm{O} \pi^{*}$ orbital. A single point electronic structure calculation at the stationary point reveals that the $\mathrm{NO}_{2}{ }^{2-}$ dianion is also an $\mathrm{N}$-centered radical with a similar $\mathrm{N}$ orbital heritage $\left(1.3 \% \mathrm{~N} 2 \mathrm{~s}\right.$ and $\left.59 \% \mathrm{~N} 2 \mathrm{p}_{\mathrm{x}}\right)$ as in Lewis acid capped 4. The inductive effect of the Lewis acid bound to the nitrite dianion through the $\mathrm{O}$-atoms results in greater unpaired electron density on the less electronegative $\mathrm{N}$ atom in the $\mathrm{O}-\mathrm{N}-\mathrm{O} \pi^{*}$ orbital (Fig. 3f).

Chemical Reactivity of the Nitrite Dianion. The nitrite radical dianion $\left[\mathrm{Cp}_{2}{ }_{2} \mathrm{Co}\right]_{2}\left[\left(\mathrm{C}_{6} \mathrm{~F}_{5}\right)_{3} \mathrm{~B}-\mathrm{ONO}-\mathrm{B}\left(\mathrm{C}_{6} \mathrm{~F}_{5}\right)_{3}\right](4)$ is stable in the solid state and at room temperature in fluorobenzene solution. Since the $\mathrm{N}$ atom of nitrite dianion $\mathbf{4}$ is at the same oxidation level as NO gas $\left(\mathrm{N}_{\mathrm{ox}}=+2\right)$, we explored avenues to produce $\mathrm{NO}$ gas from 4 . Heating a fluorobenzene solution 
of 4 at $75{ }^{\circ} \mathrm{C}$ for $48 \mathrm{~h}$ leads to the formation of $\mathrm{NO}$ gas in $65 \%$ yield (Fig. $4 \mathrm{a}$ ). ${ }^{19} \mathrm{~F}$ NMR analysis of this reaction indicates multiple $\mathrm{B}\left(\mathrm{C}_{6} \mathrm{~F}_{5}\right)_{3}$ derived products, including $\left[\mathrm{Cp}^{*}\left(\eta^{5}-\mathrm{C}_{5} \mathrm{Me}_{4} \mathrm{CH}_{2}-\mathrm{B}\left(\mathrm{C}_{6} \mathrm{~F}_{5}\right)_{3}\right) \mathrm{Co}\right]$ (5) that has undergone deprotonation of the one $\mathrm{Cp}^{*}$ methyl group followed by capture by the Lewis acid $\mathrm{B}\left(\mathrm{C}_{6} \mathrm{~F}_{5}\right)_{3}$ (Supplementary Fig. 35). Mimicking proton transfer in nitrite reduction, however, addition of 2 equiv. trifluoroacetic acid to dianion $\mathbf{4}$ at room temperature triggers instant release of $\mathrm{NO}$ gas in $72 \%$ yield with 2 equiv. $\left[\mathrm{Cp}_{2}{ }_{2} \mathrm{Co}\right]\left[\left(\mathrm{C}_{6} \mathrm{~F}_{5}\right)_{3} \mathrm{~B}-\mathrm{OC}(\mathrm{O}) \mathrm{CF}_{3}\right](6)$ isolated in $80 \%$ yield (Fig. $\left.4 \mathrm{a}\right)$.

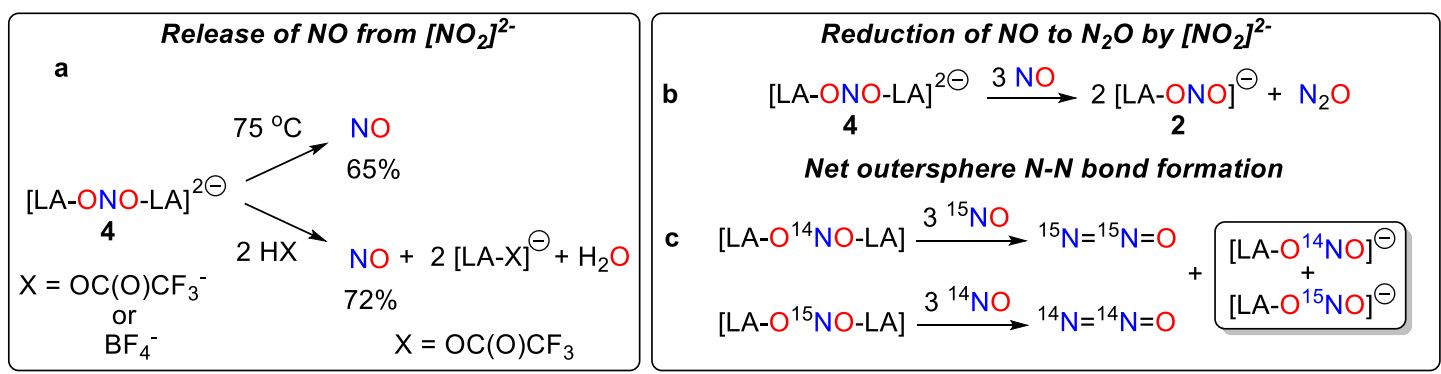

Figure 4 Reactivity of the nitrite dianion. a, Release of $\mathrm{NO}$ from nitrite dianion 4 upon heating or addition of proton sources. $\mathbf{b}$, Reduction of $\mathrm{NO}$ to $\mathrm{N}_{2} \mathrm{O}$ by nitrite dianion 4 generating 2 equiv. $\left[\left(\mathrm{C}_{6} \mathrm{~F}_{5}\right)_{3} \mathrm{~B}-\mathrm{ONO}\right]$ (2). c, Reaction with isotopically labelled $\mathrm{NO}$ reveals a net outersphere reduction of $\mathrm{NO}$ to $\mathrm{N}_{2} \mathrm{O}$.

Reaction of nitrite dianion 4 with 3 equiv. NO results in a disproportionation reaction that generates $\mathrm{N}_{2} \mathrm{O}$ and 2 equiv. [ $\left.\mathrm{Cp}_{2}{ }_{2} \mathrm{Co}\right]\left[\left(\mathrm{C}_{6} \mathrm{~F}_{5}\right)_{3} \mathrm{~B}-\mathrm{ONO}\right.$ ] (2) quantified in $43 \%$ and $90 \%$ yield, respectively. Isotopic labeling experiments provide reveal that $\mathrm{N}_{2} \mathrm{O}$ forms solely from the added $\mathrm{NO}_{\text {gas. }}$ Reaction of natural abundance nitrite dianion $4-{ }^{14} \mathbf{N}$ with 3 equiv. ${ }^{15} \mathrm{NO}_{\text {gas }}$ results in the exclusive formation of ${ }^{15} \mathrm{~N}^{15} \mathrm{NO}$ while reaction of nitrite dianion $4-{ }^{15} \mathrm{~N}$ with 3 equiv. ${ }^{14} \mathrm{NO}_{\text {gas }}$ solely forms ${ }^{14} \mathrm{~N}^{14} \mathrm{NO}$ as monitored by IR spectroscopy (Supplementary Fig. 25). In each case a 1:1 mixture of monocapped nitrite anions $\left[\left(\mathrm{C}_{6} \mathrm{~F}_{5}\right)_{3} \mathrm{~B}-\mathrm{O}{ }^{14} \mathrm{NO}\right]\left(2-{ }^{14} \mathbf{N}\right)$ and $\left[\left(\mathrm{C}_{6} \mathrm{~F}_{5}\right)_{3} \mathrm{~B}-\mathrm{O}^{15} \mathrm{NO}\right]\left(\mathbf{2}-{ }^{15} \mathbf{N}\right)$ form according to ${ }^{15} \mathrm{~N}$ and ${ }^{19} \mathrm{~F}$ NMR analysis (Fig 4c).

As an initial step, we propose net electron and Lewis acid transfer from nitrite dianion $\left[\left(\mathrm{C}_{6} \mathrm{~F}_{5}\right)_{3} \mathrm{~B}-\mathrm{ONO}-\mathrm{B}\left(\mathrm{C}_{6} \mathrm{~F}_{5}\right)_{3}\right]^{2-}$ to $\mathrm{NO}$ to form $\left[\left(\mathrm{C}_{6} \mathrm{~F}_{5}\right)_{3} \mathrm{~B}-\mathrm{ONO}\right]^{-}$and the nitroxide Lewis acid adduct $\left[\left(\mathrm{C}_{6} \mathrm{~F}_{5}\right)_{3} \mathrm{~B}-\mathrm{NO}\right]^{-}$. Hybrid DFT calculations that follow the model reaction of $\mathrm{NO}_{2}{ }^{2-}$ with $\mathrm{NO}$ via an inner sphere pathway indicate favorable thermodynamics for conversion to $\mathrm{NO}_{2}^{-}$and $\mathrm{NO}^{-}$ (Supplementary Fig. 39). Calculations reveal that related reaction involving the $\left(\mathrm{C}_{6} \mathrm{~F}_{5}\right)_{3} \mathrm{~B}$-capped species is also exergonic $(-17.5 \mathrm{kcal} / \mathrm{mol})$, though not quite as favorable as for the free species $(-45.9 \mathrm{kcal} / \mathrm{mol})$ (Figure $\mathrm{S} 40)$. Stepwise capture of 2 equiv. $\mathrm{NO}$ by $\left[\left(\mathrm{C}_{6} \mathrm{~F}_{5}\right)_{3} \mathrm{~B}-\mathrm{NO}\right]^{-}$would provide the hyponitrite radical anion $\left[\left(\mathrm{C}_{6} \mathrm{~F}_{5}\right)_{3} \mathrm{~B}-\mathrm{ONNO}\right]^{-}$followed by $\left[\left(\mathrm{C}_{6} \mathrm{~F}_{5}\right)_{3} \mathrm{~B}-\mathrm{ONO}\right]^{-}$and $\mathrm{N}_{2} \mathrm{O}$ (Supplementary Fig. 40). This latter sequence follows the previously studied reaction of $\mathrm{NO}^{-}$with $\mathrm{NO}$ to give $[\mathrm{ONNO}]^{-}$and $[\mathrm{ONNONO}]^{-}$intermediates en route to $\mathrm{N}_{2} \mathrm{O}$ and $\mathrm{NO}_{2}{ }^{-} \cdot{ }^{19,20}$ 


\section{Discussion}

In summary, by employing the Lewis acid $\mathrm{B}\left(\mathrm{C}_{6} \mathrm{~F}_{5}\right)_{3}$, electron transfer and proton transfer steps in nitrite reduction become decoupled from $\mathrm{N}-\mathrm{O}$ bond scission, permitting isolation of the nitrite dianion $\mathrm{NO}_{2}{ }^{2-}$ stabilized by a redox innocent Lewis acid at each $\mathrm{O}$ atom. While strong Lewis acids such as $\mathrm{B}\left(\mathrm{C}_{6} \mathrm{~F}_{5}\right)_{3}$ enable the capture of reactive species such as $\mathrm{O}_{2}{ }^{2-21}$ or may combine with bulky, strong Lewis bases to form frustrated Lewis pair (FLP) adducts of $\mathrm{N}_{2} \mathrm{O}^{22}$ and $\mathrm{NO},{ }^{23}$ this Lewis acid enables the isolation of the unprecedented nitrite dianion 4. This new polyoxoanion with $\mathrm{N}_{\mathrm{ox}}=+2$ provides fundamental insights into the conversion of $\mathrm{NO}_{2}{ }^{-}$to $\mathrm{NO}$. Moreover, the nitrite dianion 4 is capable of further reducing $\mathrm{NO}$ to $\mathrm{N}_{2} \mathrm{O}$ with formation of the nitrite monoanion $\mathbf{2}$, connecting three nitrogen oxidation states in the global nitrogen cycle $\left(\mathrm{N}_{\mathrm{ox}}=+3,+2,+1\right)$. Use of potent, redox-innocent Lewis acids to enable the reduction of small molecules and ions without breaking bonds affords an opportunity to gain insight into the reduction of other environmentally relevant species, perhaps opening new approaches for catalysis. This is especially true for anions such as nitrate $\left(\mathrm{NO}_{3}^{-}\right)$and perchlorate $\left(\mathrm{ClO}_{4}^{-}\right)$for which transition metals that mediate electron- and oxygen-atom transfer steps, yet bind to metal sites weakly requiring assistance via non-covalent binding to facilitate oxyanion reduction. ${ }^{24}$

\section{Acknowledgements}

This work was supported by NIH (P41GM103521 to JHF, R35G124908 to KML and R01GM126205 to THW). XAS data were obtained at SSRL, which is supported by the U.S. Department of Energy, Office of Science, Office of Basic Energy Sciences under Contract No. DE-AC02-76SF00515. The SSRL Structural Molecular Biology Program is supported by the Department of Energy's Office of Biological and Environmental Research, and by NIH/NIGMS (including P41GM103393). The work at SSRL was also supported by the U.S. Department of Energy Office of Basic Energy Sciences (proposal no. 100487).

\section{Data Availability Statement}

All data necessary to support the paper's conclusions are available in the main text and the Supplementary Information. X-ray crystal structures of $\left[\mathrm{Cp}^{*}{ }_{2} \mathrm{Co}\right]\left[\mathrm{NO}_{2}\right]$ (1) $(\mathrm{CCDC} 2074366)$, $\left[\mathrm{Cp}_{2}{ }_{2} \mathrm{Co}\right]\left[\left(\mathrm{C}_{6} \mathrm{~F}_{5}\right)_{3} \mathrm{~B}-\mathrm{ONO}\right](\mathbf{2}) \quad(\mathrm{CCDC} 2074367),\left[\mathrm{Cp}_{2}{ }_{2} \mathrm{Co}\right]\left[\left(\mathrm{C}_{6} \mathrm{~F}_{5}\right)_{3} \mathrm{~B}-\mathrm{ONO}-\mathrm{B}\left(\mathrm{C}_{6} \mathrm{~F}_{5}\right)_{3}\right](3)(\mathrm{CCDC}$

2074368), $\quad\left[\mathrm{Cp}_{2}{ }_{2} \mathrm{Co}\right]\left[\left(\mathrm{C}_{6} \mathrm{~F}_{5}\right)_{3} \mathrm{~B}-\mathrm{ONO}-\mathrm{B}\left(\mathrm{C}_{6} \mathrm{~F}_{5}\right)_{3}\right] \quad$ (4) (CCDC 2074369), $\left[\mathrm{Cp}_{2}{ }_{2} \mathrm{Co}\right]\left[\left(\mathrm{C}_{6} \mathrm{~F}_{5}\right)_{3} \mathrm{~B}-\mathrm{OCOCF}_{3}\right](\mathbf{5})$ (CCDC 2074370), [Cp* $\left.{ }_{2} \mathrm{Co}\right][\mathrm{BCF}-\mathrm{F}](\mathbf{6})$ (CCDC 2074371) and $\left[\left(\eta^{5}-\mathrm{C}_{5} \mathrm{Me}_{4} \mathrm{CH}_{2}-\mathrm{B}\left(\mathrm{C}_{6} \mathrm{~F}_{5}\right)_{3}\right) \mathrm{CoCp}^{*}\right](7)(\mathrm{CCDC} 2074372)$ are available free of charge from the Cambridge Crystallographic Data Centre viawww.ccdc.cam.ac.uk/data_request/cif. Correspondence and requests for other materials or data should be addressed to THW and KML. 


\section{References}

1 Camargo, J. A. \& Alonso, Á. Ecological and toxicological effects of inorganic nitrogen pollution in aquatic ecosystems: A global assessment. Environ. Int. 32, 831-849 (2006).

2 Sebilo, M., Mayer, B., Nicolardot, B., Pinay, G. \& Mariotti, A. Long-term fate of nitrate fertilizer in agricultural soils. PNAS 45, 18185-18189 (2013).

3 Ford, C. L., Park, Y. J., Matson, E. M., Gordon, Z. \& Fout, A. R. A bioinspired iron catalyst for nitrate and perchlorate reduction. Science 354, 741-743 (2016).

4 Maia , L. B. \& Moura, J. J. G. How Biology Handles Nitrite. Chem. Rev. 14, 5273-5357 (2014).

5 Cosby, K. et al. Nitrite reduction to nitric oxide by deoxyhemoglobin vasodilates the human circulation. Nat. Med. 9, 1498-1505 (2003).

6 Basu, S. et al. Nitrite reductase activity of cytochrome c. J. Biol. Chem. 283, 2590-32597 (2008).

7 Li, H., Samouilov, A., Liu, X. \& Zweier, J. L. Characterization of the effects of oxygen on xanthine oxidase-mediated nitric oxide formation. J. Biol. Chem. 276, 24482-24489 (2001).

8 Fukuda, Y. et al. Redox-coupled proton transfer mechanism in nitrite reductase revealed by femtosecond crystallography. PNAS 113, 2928-2933 (2016).

9 Sanders, B. C., Hassan, S. M. \& Harrop, T. C. $\mathrm{NO}_{2}^{-}$Activation and Reduction to NO by a Nonheme Fe $\left(\mathrm{NO}_{2}\right)_{2}$ Complex. J. Am. Chem. Soc. 136, 10230-10233 (2014).

10 Cook, S. A. \& Borovik, A. S. Molecular Designs for Controlling the Local Environments around Metal Ions. Acc. Chem. Res. 48, 2407-2414, doi:10.1021/acs.accounts.5b00212 (2015).

11 Yakabuskie, P. A., Joseph, J. M., Stuart, C. R. \& Wren, J. C. Long-Term $\gamma$-Radiolysis Kinetics of $\mathrm{NO}_{3}{ }^{-}$and $\mathrm{NO}_{2}{ }^{-}$Solutions. J. Phys. Chem. A 115, 4270-4278 (2011).

12 Hosseininasab, V. et al. Lewis Acid Coordination Redirects $S$ - Nitrosothiol Signaling Output. Angew. Chem. Int. Ed. 59, 10854-10858 (2020).

13 Bratsch, S. G. Standard Electrode Potentials and Temperature Coefficients in Water at 298.15 K. J. Phys. Chem. Ref. Data 18, 1-21 (1989).

14 Fukuto, J. M. et al. Small Molecule Signaling Agents: The Integrated Chemistry and Biochemistry of Nitrogen Oxides, Oxides of Carbon, Dioxygen, Hydrogen Sulfide, and Their Derived Species. Chem. Res. Toxicol. 25, 769-793 (2012).

15 Morton, J. R. \& Preston, K. F. Atomic parameters for paramagnetic resonance data. J. Magn. Reson. 30, 577-582 (1978).

16 Neese, F., Hedman, B., Hodgson, K. O. \& Solomon, E. I. Relationship between the Dipole Strength of Ligand Pre-Edge Transitions and Metal-Ligand Covalency. Inorg. Chem. 21, 4854-4860 (1999). 
17 Lukens, J. T., DiMucci, I. M., Kurogi, T., Mindiola, D. J. \& Lancaster, K. M. Scrutinizing metal-ligand covalency and redox non-innocence via nitrogen K-edge X-ray absorption spectroscopy. Chem. Sci. 10, 5044-5055 (2019).

18 Sarangi, R. et al. Sulfur K-Edge X-ray Absorption Spectroscopy as a Probe of Ligand-Metal Bond Covalency: Metal vs Ligand Oxidation in Copper and Nickel Dithiolene Complexes. J. Am. Chem. Soc. 129, 2316-2326 (2007).

19 Poskrebyshev, G. A., Sahirovich, V., Lymar, S. V. Hyponitrite Radical, a Stable Adduct of Nitric Oxide and Nitroxyl. J. Am. Chem. Soc. 126, 891-899 (2004).

20 Valiev, M. \& Lymar, S. V. Structural and Mechanistic Analysis through Electronic Spectra: Aqueous Hyponitrite Radical $\left(\mathrm{N}_{2} \mathrm{O}_{2}{ }^{-}\right)$and Nitrosyl Hyponitrite Anion $\left(\mathrm{N}_{3} \mathrm{O}_{3}{ }^{-}\right)$. $J$. Phys. Chem. A. 115, 12004-12010 (2011).

21 Henthorn, J. T. \& Agapie, T. Dioxygen Reactivity with a Ferrocene-Lewis Acid Pairing: Reduction to a Boron Peroxide in the Presence of Tris(pentafluorophenyl)borane. Angew. Chem. Int. Ed. 53, 12893-12896 (2014).

22 Otten, E., Neu, R. C., Stephan, D. W. Complexation of Nitrous Oxide by Frustrated Lewis Pairs. J. Am. Chem. Soc. 131, 9918-9919 (2009).

23 Cardenas, A. J. et al. Capture of NO by a Frustrated Lewis Pair: A New Type of Persistent N-Oxyl Radical. Angew. Chem. Int. Ed. 50, 7567-7571 (2011).

24 Ford, C. L., Park, Y.J., Matson, E. M., Gordon, Z. \& Fout, A. R. A bioinspired iron catalyst for nitrate and perchlorate reduction. Science 354, 741-743 (2016). 